\title{
A new species of Cryptophion (Hymenoptera: Ichneumonidae) from southeastern Brazil
}

\author{
Helena Carolina Onody ${ }^{1} \&$ Angélica Maria Penteado-Dias ${ }^{1}$
}

\begin{abstract}
'Departamento de Ecologia e Biologia Evolutiva, Universidade Federal de São Carlos. Rodovia Washington Luiz, km 235, 13565-905 São Carlos, SP, Brazil.E-mail: helenaonody@gmail.com; angelica@ufscar.br
\end{abstract}

\begin{abstract}
Cryptophion Viereck, 1913 is a small Neotropical genus of Campopleginae, with seven described species, two recorded from Brazil. In this paper, a new species from the Atlantic Forest of southeastern Brazil is described and illustrated. In addition, a key to the Brazilian species is provided. Cryptophion atlanticus sp. nov. (holotype female deposited in DCBU: Brazil, São Paulo, São Luiz do Paraitinga, Parque Estadual da Serra do Mar) is diagnosed by mesoscutum more or less uniformly punctate, except the notaular region with coarser and irregular rugae, scutellum bearing irregular lateral longitudinal rugae; forewing with areolet not distinctly petiolate above and hind tarsal claw pectinate, but with a large space in the middle, and distinctly longer than the arolium.
\end{abstract}

KEY WORDS. Campopleginae, Insecta, Neotropical region, parasitoid, taxonomy.

Ichneumonidae is the largest hymenopteran family, with more than 24,000 species described worldwide (Yu et al. 2012), though estimates suggest that this number exceeds 100,000 (GAULD 2002). For the most part, this contrast between estimated and recorded richness owes to unaccounted species in the Neotropical region, for which only about 4,000 species have been described so far (Yu et al. 2012), but many more are believed to exist.

Cryptophion Viereck, 1913 is a small Neotropical genus of Campopleginae with seven described species from Belize, Brazil, Costa Rica, Mexico, Paraguay and Venezuela (GAuld \& JANzeN 1994, Yu et al. 2012, OnoDy et al. 2013). The genus belongs to the Cryptophion genus-group, a large and very poorly studied complex of Campopleginae that comprises rather stout insects, with short ovipositors, well-developed mandibular flanges and also with a distinct ventral ridge that bears stout hairs on the hind basitarsus (GAULD \& JANZEN 1994).

Despite being focused on the Costa Rican fauna of Cryptophion, the research conducted by GAULD \& JANZEN (1994) was an important breakthrough in the taxonomic and biological knowledge of the genus. The authors described five new species, providing information about the hosts and phylogeny of the Costa Rican species. Their phylogeny also corroborated the monophyly of the genus with the following synapomorphies: a well-developed forwardly projecting flange near the lower edge of the propleuron; mesopleuron with a deep sternaular groove; propodeum short and deeply excavated longitudinally at the middle; hind legs very long and stout; metasomal tergite
II dorsoventrally depressed and subquadrate; forewing with vein with $2 \mathrm{~m}$-cu joining $\mathrm{M}$ opposite or slightly distal to 3rs-m and antenna with flagellum bearing 45 or more segments, with the central flagellomeres subquadrate to transverse. GAULD \& JANZEN (1994) also identified specimens of C. espinozai Gauld \& Janzen, 1994 in Lavras and Felixlândia, state of Minas Gerais, Brazil. ONoDy et al. (2013) presented geographic range extensions for this species and recorded Cryptophion guillermoi Gauld \& Janzen, 1994 for the first time in Brazil. According to GAULD \& JANZEN (1994), Cryptophion species develop as koinobiont endoparasitoids of Sphingidae or Saturniidae (Lepidoptera) larvae.

In this paper, we describe a new species from the Brazilian Atlantic Forest and also provide a key to the species of the genus recorded from the country.

\section{MATERIAL AND METHODS}

The new species described in this study is based on material collected while working on the INCT/HYMPAR project. In an attempt to find additional specimens of the new species we searched the collections of the MZUSP (Museu de Zoologia da Universidade de São Paulo) and UFES (Coleção Entomológica da Universidade Federal do Espírito Santo), but did not find any.

In addition to consulting the original descriptions of species (Cresson 1874, Viereck 1913, Gauld \& JANZEN 1994), we examined type specimens and non-type specimens of Cryptophion species deposited in the INBio collection (Santo Domingo de Heredia, Costa Rica), except C. strandi Viereck, 1913. 
Images were obtained from a Leica M205C stereomicroscope attached to a Leica DFC 295 video camera. Images were combined using Leica LAS (Leica Application Suite V3.6.0) and the scanning electron microscope images from Quanta 250 Scanning Electron Microscope (FEI) in a low vacuum mode.

Maps with distribution of the Brazilian species were obtained using QGIS (2015, version 2.2.0) software for all known occurrences data, including records from GAULD \& JANZEN (1994) and ONODY et al. (2013).

The type material of the new species is deposited at the Departamento de Ecologia e Biologia Evolutiva da Universidade Federal de São Carlos (DCBU) and Museu de Zoologia da Universidade de São Paulo, Brazil (MZUSP).

\section{TAXONOMY}

\section{Cryptophion atlanticus sp. nov.}

Figs. 1-7

urn:Isid:zoobank.org:act:2E441E79-7795-4216-B231-3B2A2B1236E8

Description. Holotype female (Fig. 1). Head with antenna stout and 52 flagellomeres; interocellar distance 1.5 times orbital-ocellar distance; lateral ocellus separated from eye by 0.75 times its own diameter; malar space 0.5 times as long as basal width of mandible (Fig. 3); occipital carina moderately developed mediodorsally, slightly broadened lateroventrally. Mesoscutum more or less uniformly punctate, except the notaular region with coarser and irregular rugae (Fig. 4); scutellum bearing long and dense yellow pubescence, rugose, with irregular lateral longitudinal rugae (Fig. 5). Mesopleuron striate diagonally, with speculum mostly smooth and polished, the ventral area rugose to coarsely punctate; sternaular groove complete and strongly impressed. Posterior transverse carina of mesosternum lateromedially weakly produced into rounded lobes that are separated by a shallow concavity. Propodeum rugose-reticulate, with apophyses strongly developed, higher than broadly basally; upper rim of hind coxal socket with a distinct apophysis-like projection. Hind tibia strongly compressed, hind basitarsus 1.2 times as long as segments 2-5; hind tarsal claw pectinate, but with a large space in the middle, distinctly longer than the arolium (Fig. 6). Forewing length $15 \mathrm{~mm}$, with areolet more or less triangular and not petiolate above; hind wing with 8 hamuli. Ovipositor short, 0.2 times hind tibia.

Head and mesosoma black, except mouthparts yellow; tegula yellow anteriorly and blackish posteriorly. Anterior two pairs of legs predominantly yellow, femur and distal tarsal segment orange, mid coxa slightly infuscate. Hind leg with coxa black, trochanteral segments and femur reddish, blackish distally; tibia black at proximal and distal apices and centrally broadly yellow; tibial spurs and tarsus yellow with distal segment slightly orange. Metasoma with tergites I and II entirely black, segments III and IV anteriorly black, and the remaining reddish. Membrane wings more or less hyaline, with a very weak trace of blackness.

Male (Fig. 2). Similar to female except by hind leg with coxa almost entirely reddish, tibia all black with a thin yellow line, basitarsus black and the following tarsomeres black dorsally.

Distribution (Fig. 7). BRAZıL: São Paulo (São Luiz do Paraitinga and Ribeirão Grande). Specimens of the new species were collected throughout the wet season in southeast Atlantic Forest habitats

Hosts. Unknown

Etymology. The specific name (adjective, gender masculine) refers to the Atlantic Forest Biome, where the specimens were collected.

Material examined. Holotype: 1 female (DCBU 39967), BRASIL, São Paulo: São Luiz do Paraitinga (Parque Estadual da Serra
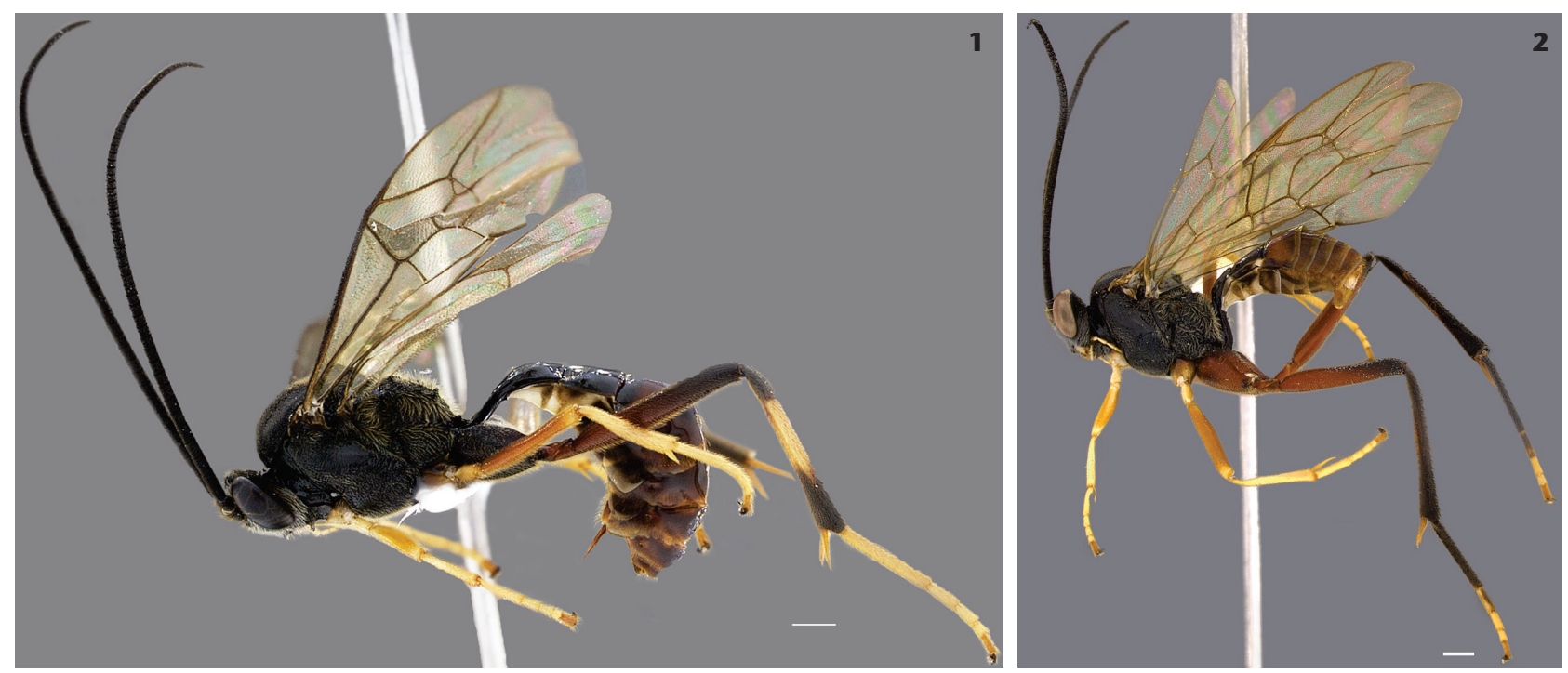

Figures 1-2. Habitus of Cryptophion atlanticus sp. nov., lateral view: (1) female holotype; (2) male paratype. Scale bar: $0.8 \mathrm{~mm}$. 

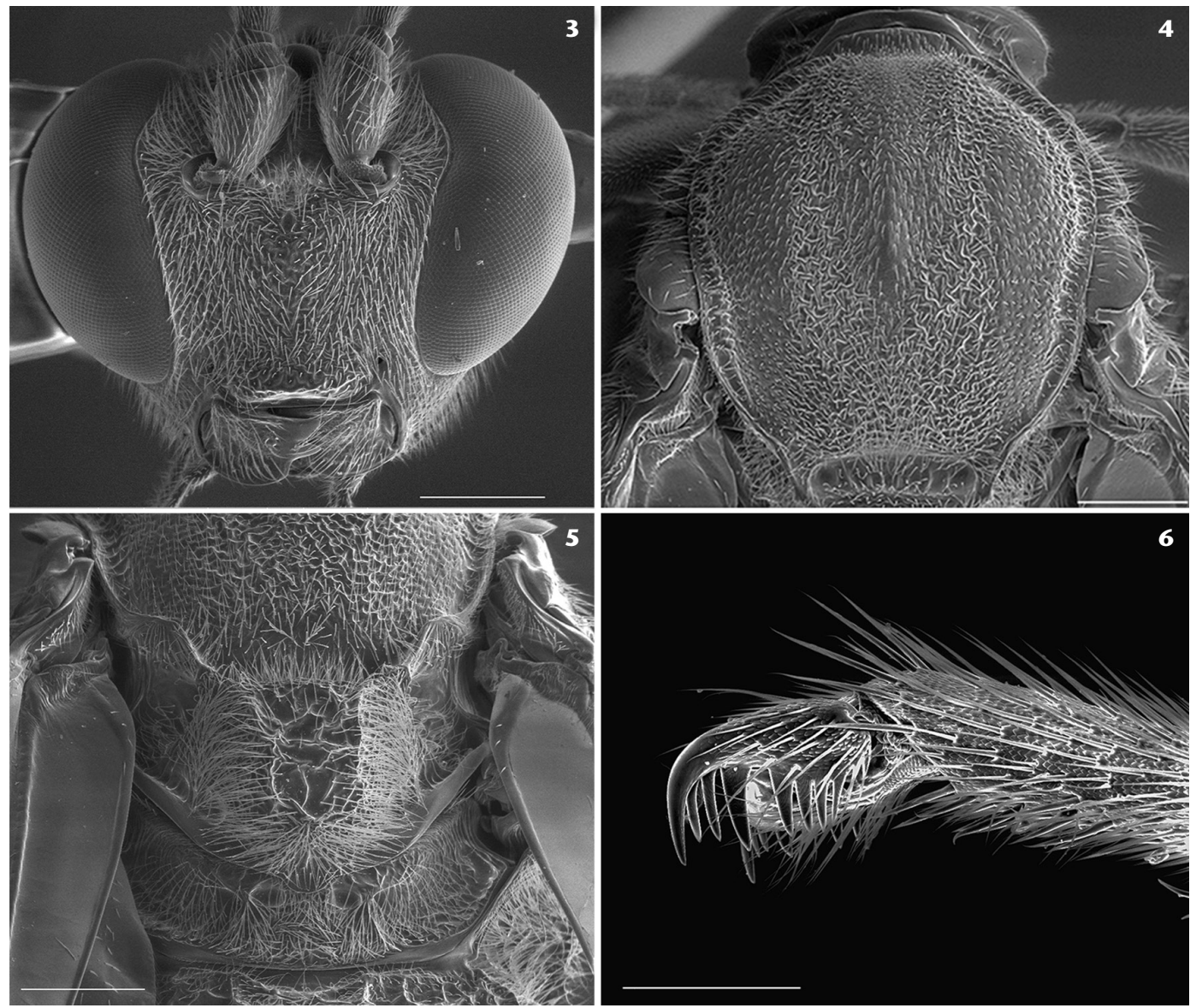

Figures 3-6. Cryptophion atlanticus sp. nov. (female, paratype): (3) head in frontal view; (4) mesoscutum in dorsal view; (5) scutellum in dorsal view; (6) hind tarsal claw. Scale bars: $2,4=500 \mu \mathrm{m} ; 3=0.5 \mathrm{~mm} ; 5=200 \mu \mathrm{m}$.

do Mar, Malaise 2, $23^{\circ} 19^{\prime} 27.2^{\prime \prime}$ S, $\left.45^{\circ} 05^{\prime} 38.5^{\prime \prime} \mathrm{W}\right), 22 . \mathrm{III} .2010$, N.W. Perioto e eq. col. Paratypes: 1 female (MZSP 53326), same data as holotype; 1 male (DCBU 35359) same data as holotype,

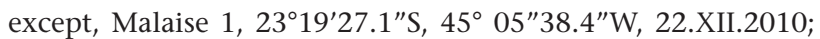
1 male (MZSP 53327) same data as holotype, except, Malaise 6, 2319'24.8”S, 4505'40.1”W, 21.XII.2010; 1 female (DCBU 39968), Ribeirão Grande, Parque Estadual Intervales, Malaise 1, $24^{\circ} 16^{\prime} 28^{\prime \prime}$, $48^{\circ} 25^{\prime} 14.8^{\prime \prime} \mathrm{W}, 22 . I I I .2010$, N.W. Perioto e eq. col.

Remarks. The specimens of Cryptophion atlanticus sp. nov. match the diagnosis of the genus and can be distinguished from all other Cryptophion by the following combination of characters: mesoscutum more or less uniformly punctate, except the notaular region with coarser and irregular rugae, scutellum bearing irregular lateral longitudinal rugae; forewing with areolet not distinctly petiolate above and hind tarsal claw pectinate, but with a large space in the middle, distinctly longer than the arolium. It differs from the other two Brazilian species also by the hind tarsal claw simple, the presence of a distinct lateral longitudinal carina on scutellum, extending for about half of its length, and the white color of its pubescence in C. guillermoi
Gauld \& Janzen, 1994, and by the interocellar distance 2.0-2.2 times the orbital-ocellar distance, hind tarsal claw with a single subapical pectinal tooth, small and not distinctly longer than arolium in C. espinozai Gauld \& Janzen, 1994. The Central American Cryptophion inaequalipes (Cresson, 1874) also has a distinct pectinate claw, but differs easily from the new species by the scutellum with a strong lateral longitudinal carina extending for about half of its length raised into tubercles posteriorly, thus scutellum is pyramidal in lateral view.

\section{Identification key for Brazilian species of Cryptophion}

1. Scutellum bearing long and dense white pubescence, and with distinct lateral longitudinal carina extending for about half of its length; hind leg with tarsal claw simple, not pectinate and tarsus entirely black (Fig. 8)....

C. guillermo

$1^{\prime}$. Scutellum bearing long and dense yellowish pubescence, and with irregular lateral longitudinal rugae (Fig. 5); hind leg with tarsal claw pectinate, or with a single pectinal tooth and females with tarsus yellow, except for the distal segment, orange

2 


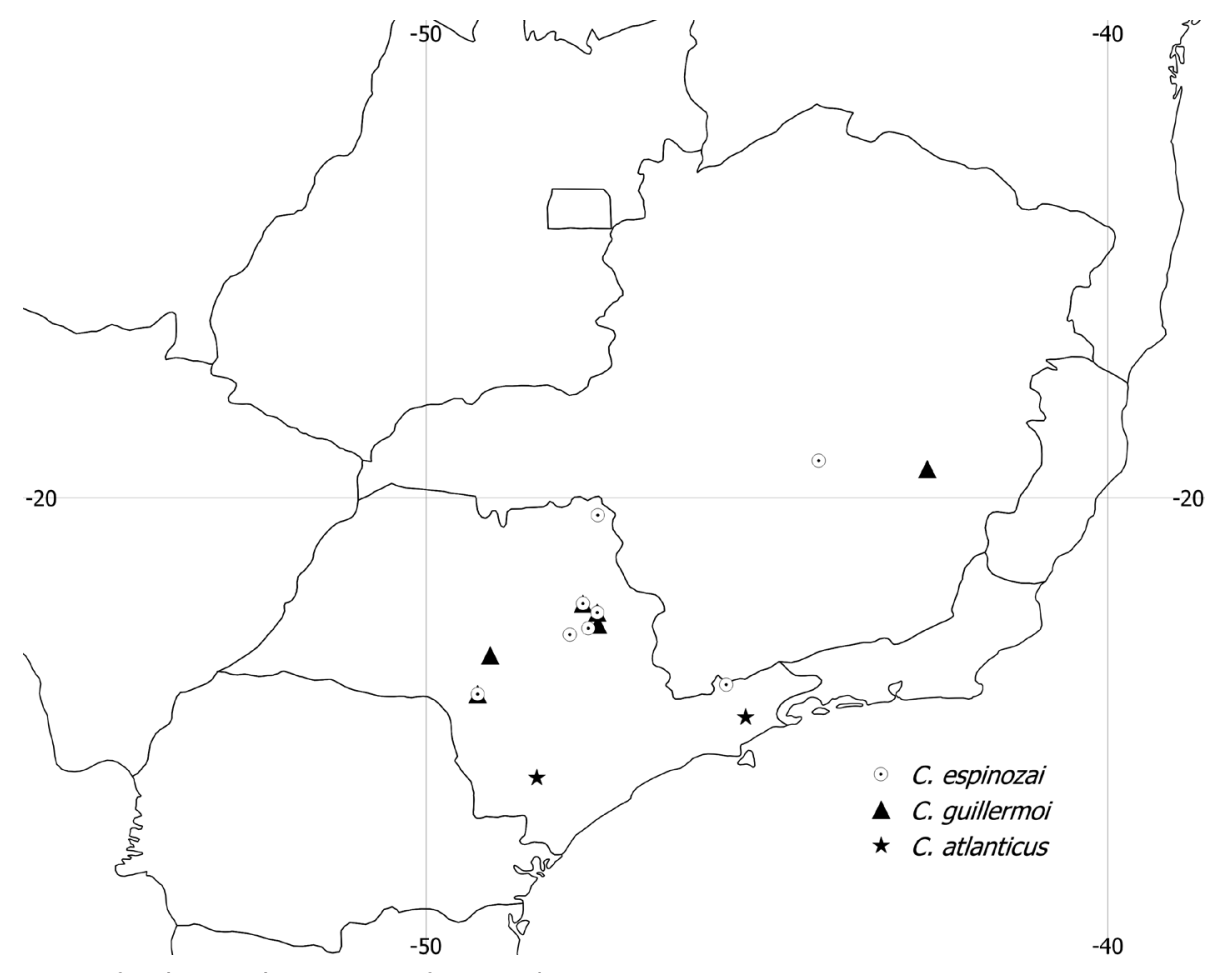

Figure 7. Distribution map for the Brazilian species of Cryptophion.

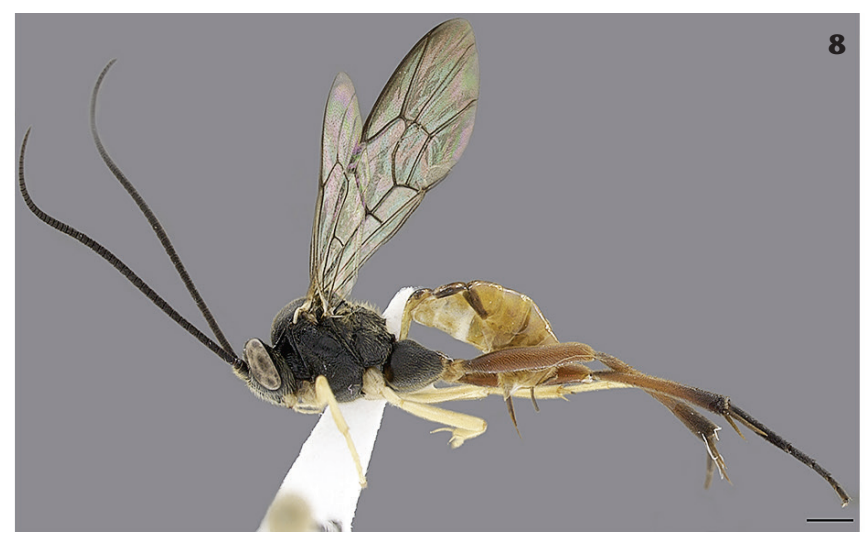

Figures 8-9. Habitus of females of Cryptophion species in lateral view:

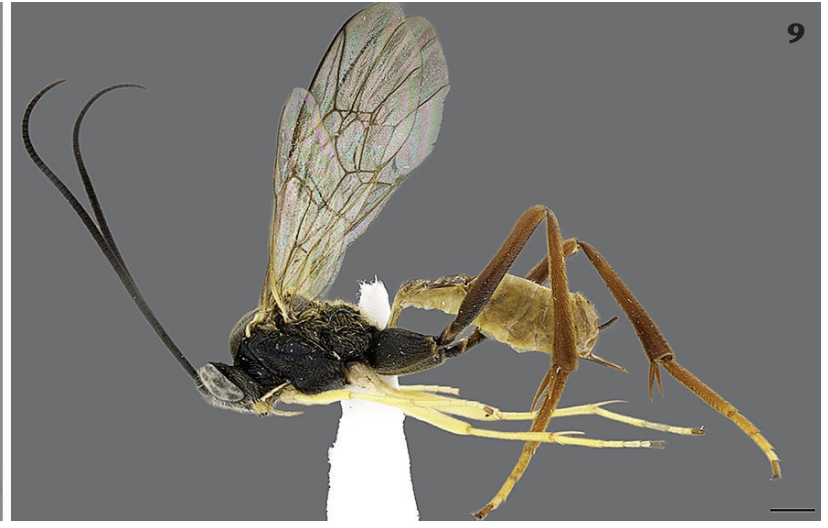

(8) C. guillermoi; (9) C. espizonai. Scale bar: $0.8 \mathrm{~mm}$.

taular region with coarser and irregular rugae (Fig. 4); hind tarsal claw pectinate, with a large space in the middle and distinctly longer than the arolium (Fig. 6)

C. atlanticus sp. nov.

\section{ACKNOWLEDGEMENTS}

We are grateful to Fundação de Amparo à Pesquisa do Estado de São Paulo (FAPESP) (Proc. 2012/158750) and the Instituto Nacional de Ciência e Tecnologia dos Hymenoptera Parasitoi- 
des da Região Sudeste Brasileira (FAPESP, Proc. 2008/57949-4; CNPq, Proc. 573802/2008-4) for the financial support. We also acknowledge the managers of Parque Estadual da Serra do Mar and Parque Estadual Intervales for allowing us to collect material, Luciana Bueno dos Reis Fernandes for providing the SEM images, and the reviewers and editor for critical reading and valuables comments on the manuscript. HCO also acknowledges Dr. Ronald Zuñiga for permitting the study of Cryptophion material during her visit to INBio (Instituto Nacional de Biodiversidad, Costa Rica).

\section{LITERATURE CITED}

Cresson ET (1874) Descriptions of Mexican Ichneumonidae. Proceedings of the Academy of Natural Sciences of Philadelphia 1873: 374-413.

GAULD ID (2002) Introduction, p. 1-8. In: GaUld I, Godoy C, UGalde J, Sithole R (Eds.). The Ichneumonidae of Costa Rica, 4. Me-

Submitted: 14 July 2015

Received in revised form: 13 November 2015

Accepted: 2 December 2015

Editorial responsibility: Ângelo Parise Pinto moirs of the American Entomological Institute 66: 1-768. GAUld ID, JANZEN DH (1994) The classification, evolution and biology of the Costa Rican species of Cryptophion (Hymenoptera: Ichneumonidae). Zoological Journal of the Linnean Society 110: 297-324. doi: 10.1111/j.1096-3642.1994.tb01477.x

Onody HC, Sandonato DL, Penteado-Dias AM (2013) First record and range extensions of Cryptophion Viereck, 1913 (Hymenoptera: Ichneumonidae) species in the Southeast region of Brazil. Check List 9(3): 653-654. doi: 10.15560/9.3.653

QGIS Development Team (2015) QGIS Geographic Information System. Open Source Geospatial Foundation Project. Available online at: http://www.qgis.org [Accessed: 24/07/2015]

VIERECK HL (1913) Descriptions of twenty-three new genera and thirty-one new species of Ichneumon-flies. Proceedings of the United States National Museum 46(2031): 359-386.

Yu DS, van Achterberg C, Horstmann K (2012). World Ichneumonoidea 2011. Ottawa, Taxapad. [Database on flash-drive. Available online at: http://www.taxapad.com]

Author contributions: $\mathrm{HCO}$ and AMPD participated equally in the preparation of this article.

Competing interests: The authors have declared that no competing interests exist. 